\title{
FREQÜÊNCIA À ESCOLA POR ESTUDANTES ENSINO MÉDIO: ANÁLISES E PERCEPÇÕES A PARTIR DE CULTURAS JUVENIS
}

http://dx.doi.org/10.5902/2176217116252

\author{
Alexsandra Matos Romio \\ Colégio Técnico Industrial de Santa Maria, Brasil. \\ Andréia Lucimar Silva de Lima \\ Universidade Federal de Santa Maria, Brasil. \\ lliane Colpo \\ Universidade Federal de Santa Maria, Brasil. \\ Claudia Cisiane Benetti \\ Universidade Federal de Santa Maria, Brasil.
}

\begin{abstract}
Resumo
Neste texto procura-se analisar as relações entre culturas juvenis e frequência à escola. Para tal, aborda-se a temática cultura juvenil, as diretrizes curriculares nacionais para o ensino médio e 0 projeto pedagógico de duas escolas de Santa Maria/RS. O objetivo geral do trabalho é compreender quais concepções e intenções jovens estudantes, de escolas de ensino médio de Santa Maria, manifestam em seus discursos acerca da instituição escolar. A metodologia de pesquisa centrou-se na perspectiva do estudo de caso e a coleta de dados envolveu a realização de entrevistas e a criação e manutenção de um perfil numa rede social denominada Facebook. $\mathrm{O}$ trabalho partiu do pressuposto de que há necessidade de conhecimento das culturas e comportamentos juvenis, em especial de quais as concepções que um grupo de jovens tem em relação ao ambiente escolar do qual participam, com vistas a promover maior envolvimento e mobilização para a aprendizagem. Após a realização do trabalho foi possível concluir que a escola apresenta distanciamento da vida social dos jovens e poucos atrativos em relação às tecnologias atuais e que, embora as diretrizes se fundamentem no pleno desenvolvimento do educando, algumas vezes os estudantes percebem a escola distante de suas expectativas.

Palavras-chave: culturas juvenis, escolarização, Facebook, diretrizes curriculares, projeto pedagógico.
\end{abstract}




\title{
SCHOOL ATTENDANCE FOR HIGH SCHOOL STUDENTS: REVIEW AND PERCEPTIONS AS FROM YOUTH CULTURES
}

\begin{abstract}
In this paper seeks to analyze the relationship between youth culture and school attendance. For such approaches to thematic youth culture, national curriculum guidelines for high school and pedagogical project of two schools of Santa Maria / RS. The general objective of the study is to understand the conceptions and intentions young students from high schools in Santa Maria, manifest in his speeches about the school institution. The research methodology focused on the perspective of the case study and data collection involved conducting interviews and creating and maintaining a profile on a social network called Facebook. The work started from the assumption that there is need for knowledge of the cultures and juvenile behavior, especially the conceptions that a group of young people have in relation to the school environment in which they participate, in order to promote greater involvement and mobilization for learning. After completion of the work can be concluded that the school offers distance social life of young people and unattractive compared to current technologies and that although the guidelines are based on full development of the students, sometimes students perceive the school away from their expectations.

Key-words: youth cultures, schooling, Facebook, curriculum guidelines, pedagogical.
\end{abstract}




\section{Introdução}

s concepções e as diretrizes aplicadas à educação estão sendo discutidas em
função dos resultados apresentados nos processos avaliativos. Novas formas
de ensinar e aprender surgem como alternativas de mudança desta realidade. Neste contexto, as escolas passam a ser definidas pela sua forma de conceber o ensino, a aprendizagem e seu método avaliativo. Passando por reformas e implantação de novos projetos pedagógicos há, também, o envolvimento de profissionais de outras áreas, como psicólogos, educadores especiais e administradores.

A escola tradicional, considerada como punitiva, segundo Narodowski e Brailovsky (2006), em que a premiação é nos acertos objetivos, constituída pelo rigor das disciplinas, passa a ser chamada de escola da dor e a escola de ensino baseado na construção do conhecimento, de forma que os conteúdos são definidos a partir da realidade dos alunos, buscando a interação social, sem avaliações tradicionais, passa a ser chamada de escola do prazer. Além dessas questões inerentes a escola em si, tem-se uma mídia fortemente envolvida, o acréscimo das inovações tecnológicas na escola, a modificação na estrutura familiar e o uso da rede mundial de computadores como ferramenta de ensino.

Neste texto se analisa quais as percepções dos jovens em relação à escola, verificando suas reações e sentimentos em relação às mudanças que as instituições têm passado, bem como o que motiva o jovem e o que o desmotiva diante dessas transformações e de que maneira o sujeito as interpreta. Com isso foi realizada uma pesquisa bibliográfica para interpretar o funcionamento das culturas juvenis e das diretrizes escolares, além dos projetos pedagógicos de escolas de ensino médio em Santa Maria e Caçapava do Sul. Concomitantemente foi efetuado um estudo de caso entrevistando jovens dessas escolas, investigando sua percepção em relação à escola. Em seguida, com base na análise documental, na observação e nas informações recebidas dos jovens estudantes, foi elaborada uma análise qualitativa, onde se busca responder o que os jovens esperam da escola.

\section{Metodologia}

A problemática desenvolvida no presente trabalho abrange o questionamento do que os jovens esperam da escola. Sendo assim, o objetivo principal foi analisar o que os jovens estudantes de diferentes escolas de ensino médio de Santa Maria e Caçapava do Sul, no Rio Grande do Sul, esperam da escola. Como específicos definiu-se conceituar e diferenciar as culturas juvenis atuais, identificar as concepções dos jovens estudantes sobre o que é a escola, como se sentem parte desse movimento e de que forma a analisam; identificar quais são as expectativas dos jovens para seu futuro e que forma a escola se alinha com isso. Finalmente realizou-se uma comparação das concepções dos jovens em relação às diretrizes das escolas analisadas.

Dessa forma, utilizou-se um estudo de caso que envolveu a realização de entrevistas com jovens estudantes de escolas de ensino médio em Santa Maria e Caçapava do Sul, no Rio Grande do Sul. A elaboração do estudo de caso seguiu os passos de Miguel et al (2010, p. 131).

Finalmente foram comparadas as concepções que os jovens possuem de suas escolas e suas expectativas com as diretrizes das escolas. Espera-se que esses dados possibilitem compreender, no que se refere ao contexto escolar, as práticas e concepções 
relacionadas com os modelos propostos pelas diretrizes escolares e verificando o que estas implicam nas intenções dos jovens estudantes.

Com a necessidade de obtenção de informações sobre os jovens, a fim de concretizar o desenvolvimento do estudo de caso proposto e obter os objetivos definidos no projeto, utilizou-se o Facebook ${ }^{1}$, propiciando um ambiente descontraído para os jovens e que permitisse um maior desenrolar do discurso sobre o que pensam da escola. Para isso, construiu-se um perfil para o personagem denominado Zoreia no portal do Facebook. Aluno regular, cansado da escola e que pretende abandonar os estudos, esse personagem foi apresentado aos alunos de três escolas de ensino médio das cidades de Santa Maria e de Caçapava do Sul. Os estudantes souberam que se trata do Projeto Curta Escola, em que o personagem criou uma página com o título do projeto dentro do Facebook para desenrolar discussões sobre seu desânimo em relação à escola e para que os participantes do estudo de caso discorressem suas posições do que pensam sobre a escola e o que esperam da mesma. O estímulo para a participação foi um prêmio sorteado entre os participantes. O acesso foi limitado aos estudantes das escolas e que projeto foi divulgado e os quais foram previamente cadastrados.

\section{Culturas juvenis e redes sociais}

As culturas juvenis são criadas e recriadas a todo o momento, o que pode ser explicado pela definição social dessa fase da vida designada juventude. É comum o uso da faixa de 15 a 24 anos na definição de juventude. Juventude sinônimo de transição, de mudanças, de um sentimento de poder quase que revolucionário. Quanto à constituição do termo juventude, segundo José Machado Pais (1997) há duas grandes linhas: a primeira relacionada à gerações passadas como sendo um grupo homogêneo, grupo cuja característica mais importante é estar vivenciando a mesma faixa de idade. A segunda linha, inclusive com a utilização do temo juventudes, se refere a grupos heterogêneos, cujas características, destacadas por Esteves e Abramovay (2007), são as múltiplas formas de interação e inserção social, regidas pelas oportunidades, facilidades e pelas possibilidades que constituem dentro da sociedade.

Numa perspectiva histórica Ribeiro (2004) relata que, a partir da Revolução Francesa, surgiu uma nova concepção de juventude, a qual passa a ser compreendida e valorada no mundo contemporâneo. Destaca-se, ainda, que até então a sociedade era mais identificada com a velhice, segundo seus padrões, símbolo de distinção social. Conforme Esteves e Abramovay (2007), com a vitória do modelo capitalista sobre o modelo absolutista monárquico, surgem ideias novas, liberdade, democracia e vida. Esteves e Abramovay (2007, p. 23) conclui que "não é de se estranhar, portanto, a associação comumente realizada entre juventude e revolução."

Desde metade do século 20 a influência da juventude na sociedade tomou proporções diferentes, seja pelo ideal de revolução e não acomodação, seja pela publicidade, pelo sentido de associarmos cada vez mais a liberdade a essa etapa da vida. Conforme Ribeiro (2004), a ideia de liberdade social pode ser cada vez mais marcada por associações relacionadas aos valores da mocidade, o corpo bem cuidado, saúde, a opção

\footnotetext{
1 Facebook é um site e serviço de rede social que foi lançada em 4 de fevereiro de 2004, operado e de propriedade privada da Facebook Inc.. 
da liberdade até mesmo de desfazer relacionamentos e a possibilidade de inúmeros recomeços afetivos e profissionais, tudo isso teria haver com uma conversão do humano em jovem.

A configuração social da atual juventude, de acordo com Pereira (apud Green e Bigum, 1998), passa pela escolarização, havendo outros fatores como os meios de comunicação, a cultura de massa, a cultura de drogas, o que a torna uma nova geração totalmente diferente das anteriores. Os autores também destacam a intimidade desta geração com as tecnologias de informação e comunicação e a importância do entendimento dessa nova configuração de juventude pelos profissionais da educação, pois, segundo Pereira (2007), esta realidade não esta recebendo a atenção que merece, o que esta provocando um distanciamento na relação aluno-escola.

Para entender como funciona a cultura jovem na atualidade, torna-se necessário a construção de uma relação saudável entre as gerações e no ambiente escolar. Pais (2006) explica que as culturas juvenis são performativas, nem sempre se enquadram nas culturas que a sociedade lhes impõe: "perante estruturas sociais cada vez mais fluidas, os jovens sentem a sua vida marcada por crescentes inconstâncias, flutuações, reversibilidades". Tendem a tornar relativos os estatutos sociais pré-estabelecidos. Surge então, a idealização do hoje, do presente: o importante é viver o dia-a-dia, pois não existe mais garantia do futuro, o diploma não traz a certeza do trabalho, o casamento pode ser desfeito com o divórcio.

Assim, é comum os jovens assumirem riscos "para transcender a natureza anódina do cotidiano" (Pais, 2006, p. 11). Nesta perspectiva a cultura juvenil busca a liberdade, a fuga do cotidiano, já que o mesmo não lhe traz garantias. O mesmo autor destaca alguns exemplos de culturas, como rap que utiliza palavrões em suas composições como forma de insultar, provocar a sociedade, chamar a atenção em prol de movimentos de justiça. Outro exemplo é a admiração a grupos de criminosos, muitas vezes sem participação nesses grupos, a cultura do grafite que supostamente denuncia o preenchimento de espaços antes vazios.

A grande maioria dos jovens, segundo Crespo et al (2009), utiliza o Facebook em função de sua popularidade. Outro motivo seria a pressão social que a rede social gera, pois os colegas insistem. Recebem-se muitos avisos pela caixa postal para que se faça parte da rede ou o indivíduo é ridicularizado por ainda não fazer parte, por que todos possuem um perfil. Outra razão é o compartilhamento de fotos, a possibilidade de manter contato com amigos distante, a ampliação do círculo social e os aplicativos como jogos, possibilidade de reuniões e atividades de interação (Crespo et al, 2009).

Ainda na concepção de Crespo et al (2009), o Facebook proporciona a disponibilidade de diversos serviços, o que é uma vantagem, pois os jovens comentam que lembram dos aniversários dos amigos, podem conversar pelo portal, é possível trocar informações sobre viagens, lugares, lojas e serviços. Também funciona como calendário e ainda existe a opção de presentes virtuais e mensagens gratuitas, o que é economicamente vantajoso. Assim como existem as vantagens, o Facebook possui desvantagens, como o consumo de tempo, exposição excessiva, muitas mensagens recebidas na caixa postal (Crespo et al, 2009).

Já para Oliver (2011), há uma grande perda de identidade por trás do Facebook. 0 autor salienta que é possível antecipar a própria artificialidade dos perfis pessoais no 
Facebook, o que pode agravar o tipo de comportamento socialmente artificial encontrado entre os grupos economicamente competitivos, em que o interesse é promover-se de qualquer maneira. Rodriguéz (2011) faz um contraponto, sugerindo que as redes sociais podem ser movimentos que geram transformações e que as transformações são válidas.

\section{Atribuições das escolas}

A Lei de Diretrizes e Bases tem, sobretudo, um papel legitimador das grandes reformas que estão sendo feitas com grande velocidade na educação, tanto por iniciativa do Ministério da Educação, quanto de alguns Estados e municípios (Michele Chritople, 2005). Segundo a LDB (1996), a educação, dever da família e do Estado, inspirada nos princípios de liberdade e nos ideais de solidariedade humana, tem por finalidade o pleno desenvolvimento do estudante, seu preparo para o exercício da cidadania e sua qualificação para o trabalho. A escola, em tese, é o lugar privilegiado para o desenvolvimento do princípio da "liberdade de aprender, ensinar, pesquisar e divulgar a cultura, o pensamento, a arte e o saber" (art. o, inciso I).

Dessa forma, na concepção da Lei de Diretrizes e Bases, as funções da escola brasileira, no campo mais formal, podem ser apreendidas já no art. $1^{\circ}$, quando se assinala: "A educação abrange os processos formativos que se desenvolvem na vida familiar, na convivência humana, no trabalho, nas instituições de ensino e pesquisa, nos movimentos sociais e organizações da sociedade civil e nas manifestações culturais".

Já o ensino médio, na concepção de Abramoway (2005), foi configurado pela LDB como a última etapa da educação básica. Esse fato aconteceu num momento em que a sociedade contemporânea vive alterações de ordem tecnológica e econômico-financeira. O desenvolvimento científico e tecnológico das últimas décadas não só transformou a vida social, como causou profundas alterações no processo produtivo que intelectualizou, tornou tecnológico, e passou a exigir um novo profissional, diferente do requerido pelos modelos taylorista e fordista de divisão social de trabalho. A sociedade contemporânea aponta para a exigência de uma educação diferenciada, uma vez que a tecnologia está impregnada nas diferentes esferas da vida social (Abramoway, 2005).

Para a Lei de Diretrizes e Bases, no art. $47, \S 2^{\circ}$, os alunos que tenham extraordinário aproveitamento nos estudos, demonstrado por meio de provas e outros instrumentos de avaliação específicos, aplicados por banca examinadora especial, poderão ter abreviada a duração dos seus cursos, de acordo com as normas dos sistemas de ensino. Art. $36, \S 2^{\circ}$, estabelece que "o ensino médio, atendida a formação geral do educando, poderá prepará-lo para o exercício de profissões técnicas".

Aponta-se, ainda, para a universalização do acesso à escola básica e para uma formação voltada à construção da cidadania, o que impõe o tratamento na escola de questões sociais atuais. Para que esta tarefa seja realizada é preciso que os professores tenham uma sólida e ampla formação cultural. Situações de ensino e aprendizagem são situações comunicativas, nas quais alunos e professores coparticipam, concorrendo com a influência igualmente decisiva que o êxito do processo (CNE, 2002).

Dessa forma, de acordo com CNE (2002), os indivíduos podem construir seus conhecimentos em interação com a realidade, com os demais indivíduos e colocar em uso suas capacidades pessoais. O que uma pessoa pode aprender em determinado momento depende das possibilidades delineadas pelas formas de pensamento de que dispõe 
naquela fase de desenvolvimento, dos conhecimentos que já construiu anteriormente e das situações de aprendizagem vivenciadas. É, portanto, determinante o papel da interação que o indivíduo mantém com o meio social e, particularmente, com a escola (CNE, 2002).

Para uma grande maioria de jovens, estudos revelam (Brasil, 2003) que a escola representa, via de regra, um espaço distante de seus interesses pessoais, um polo de conflitos entre realidades excludentes, o que cria uma dicotomia entre vida pessoal e educação formal. Essa imagem negativa, fomentada na infância, ganha contornos mais sólidos na juventude, interferindo com mais consistência no período que corresponde ao ensino médio (Brasil, 2003).

\section{Concepções da escola em relação as suas funções}

Com o intuito de observar âmbitos escolares diferentes em suas estrutura e funções, selecionaram-se três escolas. A primeira estadual de ensino médio, a segunda estadual de ensino técnico e a terceira federal também de nível técnico.

Segundo sua responsável, a primeira ${ }^{2}$, a Escola Estadual de Ensino Médio Dom Antônio Reis, criada em 29 de setembro de 1961, participa do Ensino Médio Inovador e teria como mantenedora a Secretaria da Educação do Estado do Rio Grande do Sul. Neste período atendeu alunos na educação infantil, ensino fundamental, EJA e ensino médio, sendo este a partir de junho de 2009. A escola localiza-se no bairro Salgado Filho, em Santa Maria. Atualmente funciona nos três turnos, sendo que pela manhã tem sete turmas do ensino Fundamental com 180 alunos. No período da tarde são 148 alunos divididos em cinco turmas do Ensino Fundamental. Já no turno da noite a escola conta com seis turmas do EJA, ensino fundamental, com 80 alunos. No Ensino Médio regular uma turma de cada série, num total de 60 alunos. A escola também conta com 32 professores e 9 funcionários. O regimento escolar do ensino fundamental possui nove anos, o projeto político-pedagógico está em atualização e os planos de estudos estão sendo revisados neste ano.

Conforme a resolução n. 2, que define as Diretrizes Curriculares Nacionais para o Ensino Médio, o trabalho pedagógico deve se basear na formação integral do estudante, na pesquisa, na historicidade dos conhecimentos e dos sujeitos, na integração de conhecimentos gerais e na perspectiva da interdisciplinaridade e da contextualização, no reconhecimento e aceitação da diversidade e da realidade concreta dos sujeitos do processo educativo. Para tal, é um trabalho coletivo que exige atitude que evidencie interesse por conhecer, compromisso com o aluno e ousadia para tentar o novo em técnicas e procedimentos, de articulação do estudo da realidade e produção de conhecimento com vistas à transformação.

Já a segunda escola ${ }^{3}$, a Escola Técnica Estadual Dr. Rubens da Rosa Guedes, localiza-se em área rural próxima a sede do município de Caçapava do Sul, numa distância de 5km. Trata-se de uma escola técnica estadual que nasceu como Ginásio Agrícola, o qual funcionou de 10 de maio de 1969 a 1975. Em 1977 reiniciou suas atividades como Centro Rural de Ensino Supletivo - Cres -, quando houve adaptação dos atuais prédios. No ano de 2003 foi transformada em ensino fundamental com ênfase em

2 De acordo com informações recebidas por e-mail da coordenadora pedagógica.

3 Segundo portal da escola http://www.eterrg.com.br/.

Regae: Rev. Gest. Aval. Educ.

Santa Maria

v. 4

ก. 7

Jan./jun. 2015

p. $7-24$ 
agropecuária. Em 2007 foi acrescido o ensino médio e em 2008 a Escola TécnicaHabilitação em Agropecuária. Em agosto de 2010 formou-se a primeira turma do Curso Técnico em Agropecuária.

A escola dispõe de uma área de 78,09 hectares e a área construída é de 2.644,65 metros quadrados. Possui diferentes setores produtivos que oportunizam aos alunos a aplicação da prática dos ensinamentos teóricos. A instituição também oferta ensino em tempo integral e para os alunos oriundos do meio rural e de outros municípios oferta 0 sistema de internato gratuito. Abrange o Município sede e outros municípios. A escola tem em vista o repensar do ensino aprendizagem, pretendendo um ensino de forma a promover as formações humanas, culturais, social e esportiva, de acordo com os interesses e necessidades por um trabalho que permita o crescimento integral do estudante.

A terceira escola ${ }^{4}$ iniciou suas atividades em 4 de abril de 1967, com a oferta de cursos Técnicos de Nível Médio em Eletrotécnica e Mecânica. Propunha-se formar mão de obra qualificada para atender ao processo de desenvolvimento industrial que a região Central do Estado. Nos 45 anos de atuação a cultura pedagógica produziu diferentes identificações, relativas a quatro fases de seu processo histórico: a primeira, fase de implantação, de 1963 até 1969, correspondeu ao período de criação da escola, quando esta refletiu as transformações técnicas e industriais, bem como os interesses políticos do país no pós-64. A segunda, fase de afirmação, de 1970 até 1984, quando buscou afirmarse e ser reconhecida como um centro de formação técnica de qualidade pela colocação dos primeiros técnicos no mercado de trabalho regional. A terceira, fase de revisão, de 1985 até 2003, época em que o país vivenciou um período de redemocratização, que refletiu no espaço da escola pela produção de uma cultura político-pedagógica de participação gradativa da comunidade nas decisões tomadas em âmbito escolar. A quarta, fase de renovação, envolve os últimos anos, quando passou a ofertar cursos superiores de tecnologia e cursos técnicos profissionalizantes nas modalidades à distância e Educação Profissional para Jovens e Adultos.

Desde sua implantação os primeiros cursos oferecidos são mantidos, porém, redimensionados para outras modalidades ou turnos. Um exemplo está na oferta de cursos técnicos noturnos, no que foi uma das pioneiras no país. Para viabilizar o acesso dos alunos trabalhadores à educação profissional, em 1978 passou a oferecer o Curso Técnico em Eletrotécnica Noturno e, em 1987, o Curso Técnico em Mecânica Noturno, ambos na forma subseqüente ao ensino médio.

A terceira escola é uma escola técnica federal, vinculada à UFSM. Tendo por missão "educar para uma cidadania consciente" e baseando-se em valores como liberdade, justiça, cidadania, consciência ética, compromisso social, democracia, educação, identidade, criatividade e empreendedorismo, procura atender a três premissas básicas: formação científica, tecnológica e humanística sólidas, que possibilitem a alunos e professores flexibilidade diante das mudanças apresentadas constantemente pelo atual processo histórico. Nessa perspectiva, sua prática educativa é constantemente redirecionada, repensando os aspectos didático-pedagógicos relacionados ao processo de ensino e aprendizagem da educação profissional de nível médio e superior,

${ }^{4}$ Conforme consta na página virtual da escola http://www.ctism.ufsm.br/

\begin{tabular}{l|l|l|l} 
Regae: Rev. Gest. Aval. Educ. & Santa Maria & v. 4 & n. 7
\end{tabular}

Jan./jun. 2015

p. $7-24$ 
adequando-se aos novos contextos, visando ao desenvolvimento de conhecimentos e atitudes que contribuam para as interferências sociais as quais somos constantemente desafiados.

\section{Concepções dos jovens em relação à escola}

Conforme metodologia descrita anteriormente, a partir do perfil criado no Facebook e com os jovens das escolas participantes devidamente cadastrados, iniciou-se o processo de coleta e transcrição dos dados. Os jovens tiveram cinco semanas para a realização dos comentários diante das cinco postagens feitas pelo personagem Zoreia, uma por semana. Os resultados são argumentações sobre a mensagem das imagens descritas a seguir, que envolvem temas do ambiente escolar, promovendo opiniões sobre quais as concepções dos jovens diante da escola atual.

\section{A escola como um ponto a ser passado}

Considerando como tema o fato de uma determinada escola estar em decadência, prestes a fechar as portas, os jovens participantes da entrevista sugeriram que essa escola seria um lugar pela qual os alunos perderiam totalmente o interesse e cuja possível solução seria a atualização do ambiente escolar, deixando-a mais interessante, ou seja, mais jovem. Pode-se entender o sentido dessa afirmação como uma espécie de insatisfação pelo meio, ou seja, que estaria desatualizado diante das culturas juvenis, sendo assim, seria preciso tornar a escola mais juvenil para fazê-la interessante. Por outro lado, tirar a escola do ambiente hostil, mudando do lugar em que atrativos externos desprendem a atenção para o foco da mesma, surge entre os entrevistados como outra possibilidade de contribuição para a sua permanência.

Imagem 1

Escola: passa-se o ponto.

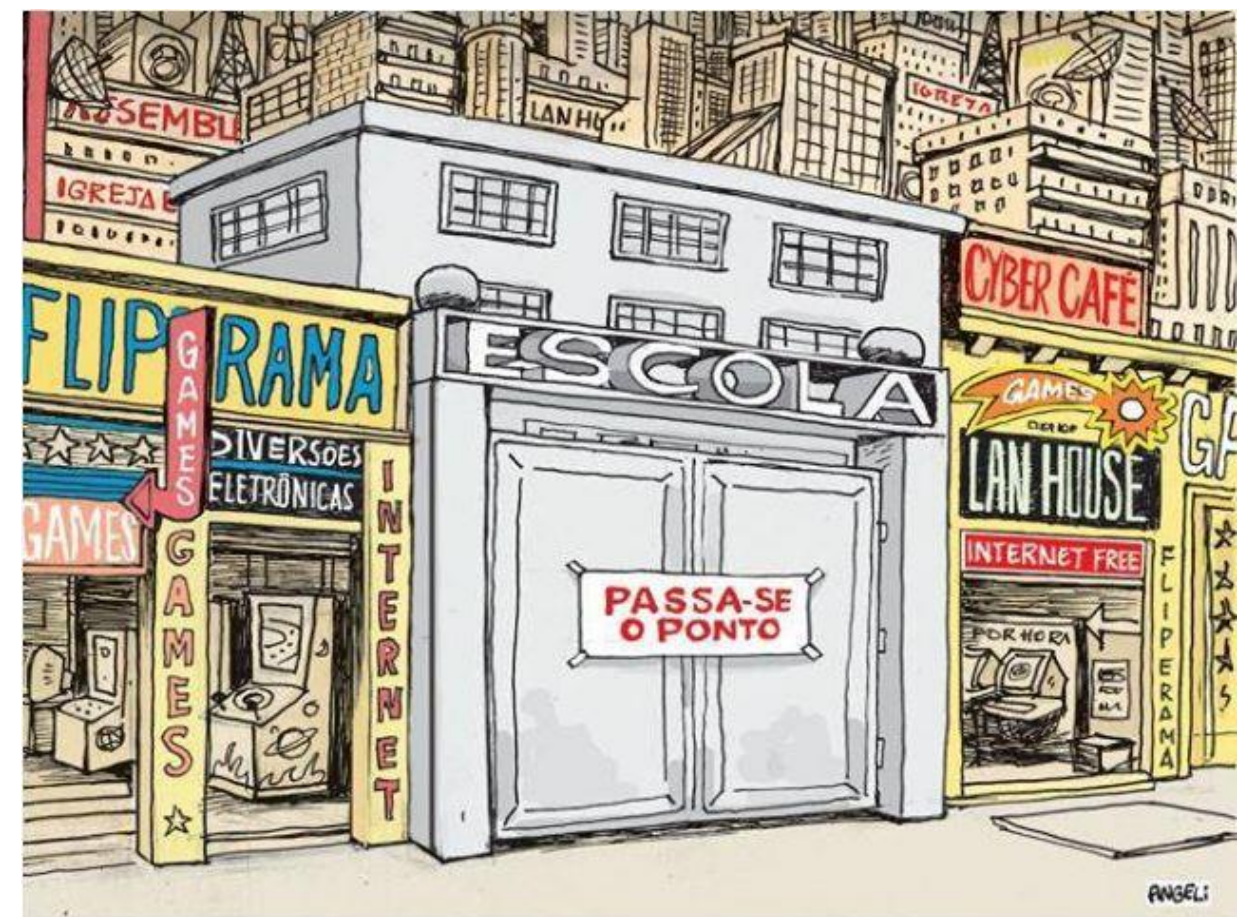


Outro motivo para a decadência da escola, sugerido entre os entrevistados, é a revolução tecnológica que disponibiliza atrativos variados para os jovens, mantendo-os envolvidos com jogos, amigos, cinema e lojas, aos quais seriam mais importantes do que a escola em si, uma vez que isso os afeta, já que as tecnologias possibilitam o envolvimento com situações mais divertidas e interessantes. Segundo outra opinião sobre responsabilidade da revolução tecnológica "no meio de tantas coisas coloridas, uma escola flagrantemente cinza, com um aspecto de formalidade extrema sendo exalado pela sua edificação. Deveras que aluno nenhum vá se focar tanto nos estudos mediante a vizinhança colorida de lan-houses e fliperamas." Ao levar-se em consideração que os jovens sujeitos são atraídos por cores, luzes, imagens, movimento e que a mídia faz uso dessas impressões para vender seus produtos, uma solução para a decadência dessa escola seria copiar a mídia para benefício.

Segundo os entrevistados "os tempos mudam e os jovens gostam da nova era. Poderia-se potencializar a aceitação dos estudos pelos jovens se ele fosse dinamizado, com maior uso de tecnologias e cultura atual nas aulas." A intensificação do consumo e o ato de tornar os ambientes economicamente lucrativos, incluindo as escolas e seus prédios, demonstra certo descaso com a educação segundo outra opinião, o que poderia ser motivo para o fechamento da escola: "os jovens não pensam que sem estudo não chegaram a lugar algum mesmo com toda a tecnologia." Há também a possibilidade da extinção da escola para o desenvolvimento de conhecimentos no ambiente doméstico, a fim de envolver maior quantidade de informações em menor espaço de tempo, no entanto, para os jovens entrevistados, a convivência proporcionada pelo ambiente escolar é fundamental e necessária.

\section{As impressões pelas vestimentas}

O diálogo entre uma mulher com idade avançada e um rapaz com roupas extravagantes e largas remete, para os jovens que opinaram, para a mudança de uma época para outra e a velocidade com que as transformações ocorrem e que em geral "cada um veste o que tem e o que quer", demonstrando tentativa de independência e libertação através do que se usa para vestir. Ainda, "o que os outros pensam é problema deles, se eu me sentir bem com uma roupa é aquela que vou usar, se eu não gosto da roupa que está na moda", sugerindo identificação própria e repúdio por imposições. Além de "não vou usar só para que achem q sou descolada e tal. Visto aquilo que tenho condições de comprar e o que eu me sinto bem." Caracterizando opinião própria e de alguma maneira dúvida entre ter e sentir. Tendo em vista que a escola é palco dessas opiniões e divergências e que a moda se comporta de maneira diferente para grupos diferentes, têm-se no ambiente escolar diferentes padrões de expressão sobre o mesmo tema que é independência e libertações. 
Imagem 2

Vestimentas.

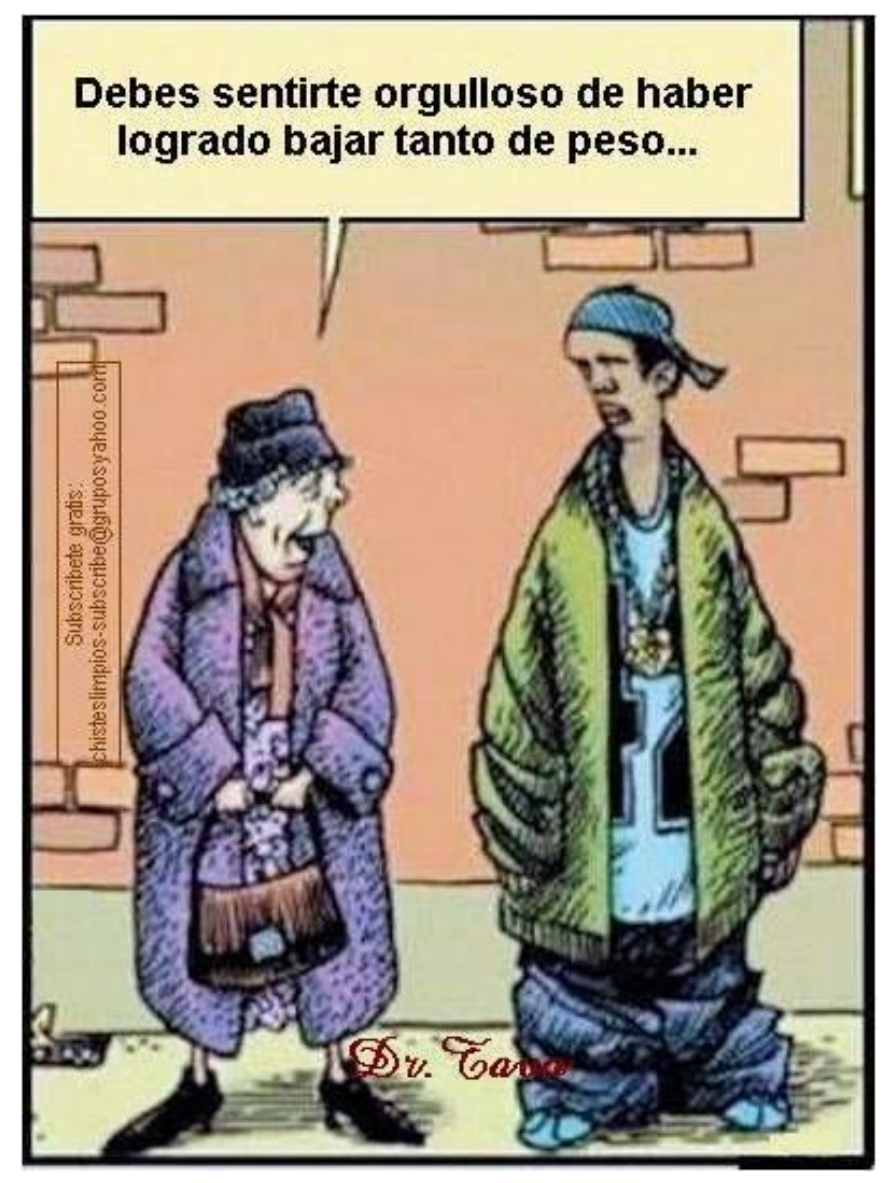

De acordo com os comentários dos jovens existem significados diferentes entre os pontos de vistas das diferentes gerações, ou seja, a forma de vestir-se representa uma cultura em um determinado recorte de tempo e a compreensão desse significado cultural diverge entre os tempos de um indivíduo e de outro. Isso fica claro quando se analisa as frases dos jovens: "O mundo mudou muito desde a época dos nossos avós" ou então "é uma questão de costume, a senhora não está acostumada com roupas diferentes, para ela isso significa outra coisa que para ele". O que identifica mudança e significado.

Ou ainda comentários como "Essa senhora só está de acordo com a mentalidade das pessoas da época dela", caracterizando épocas distintas e acordos ou significados recortados de momentos diferentemente vivenciados. A mesma proposta fica clara em "nossos avós também devem achar engraçado certas roupas que usamos... é tudo uma questão de ondas, moda." A falta de compreensão entre as gerações fica perceptível também no comentário: "Talvez a velhinha não esteja entendendo como a moda muda: como foi das roupas que os jovens usavam na sua época até essas coisas pesadas e extravagantes - e, pior, como isso é considerado normal".

Considerando-se a escola como se fosse uma roupa e que os tipos de vestimentas caracterizam uma época e por isso mudam de uma época para outra, questiona-se quando e quanto é a moda escola. Até que recorte temporal ela será aceita, como algo da onda. Para essa concepção foram analisados dois pontos de vista, ou seja, o aspecto da 
escola - instituição - que é moda: "Acredito que dependendo da escola sim. Se fulano estuda na escola tal que é uma escola de alto custo, quem tá nessa escola tá na moda. Quem estuda em escola pública tá fora da moda." Ainda existe o aspecto da escola enquanto meio "creio que não, estamos na escola porque é necessário para a vida, não temos escolha". E também "na verdade eu acho que sim. Pois apesar da velha ideia de escola ser a mesma, toda a infraestrutura e os meios podem alterar-se com o tempo e com o surgimento de novas tecnologias. Podem tornar-se mais modernos, assim como as roupas do nosso amigo da imagem."

\section{Ética na sociedade atual}

$\mathrm{Na}$ imagem desse tópico tem-se uma sala de aula em que ocorre uma prova, cuja questão é a importância de ser ético hoje em dia. Quatro adultos estão sendo testados, dos quais um deles aparece concentrado respondendo a questão e os outros três ao seu redor copiam as respostas. Questiona-se sobre a ética na sociedade atual, uma vez que é necessário avaliar a aprendizagem referente aos conteúdos trabalhados, mas até que ponto se está avaliando os conteúdos ou avaliando os estudantes e até em que medida os estudantes estão mostram seu desenvolvimento do conteúdo trabalhado. Segundo os jovens, a tecnologia aparece novamente como um ponto de referência importante, uma vez que "com a tecnologia e a velocidade de relações e transferências de informação, deve-se manter pelo menos um pouco de humanidade."

Imagem 3

Ética na sociedade.

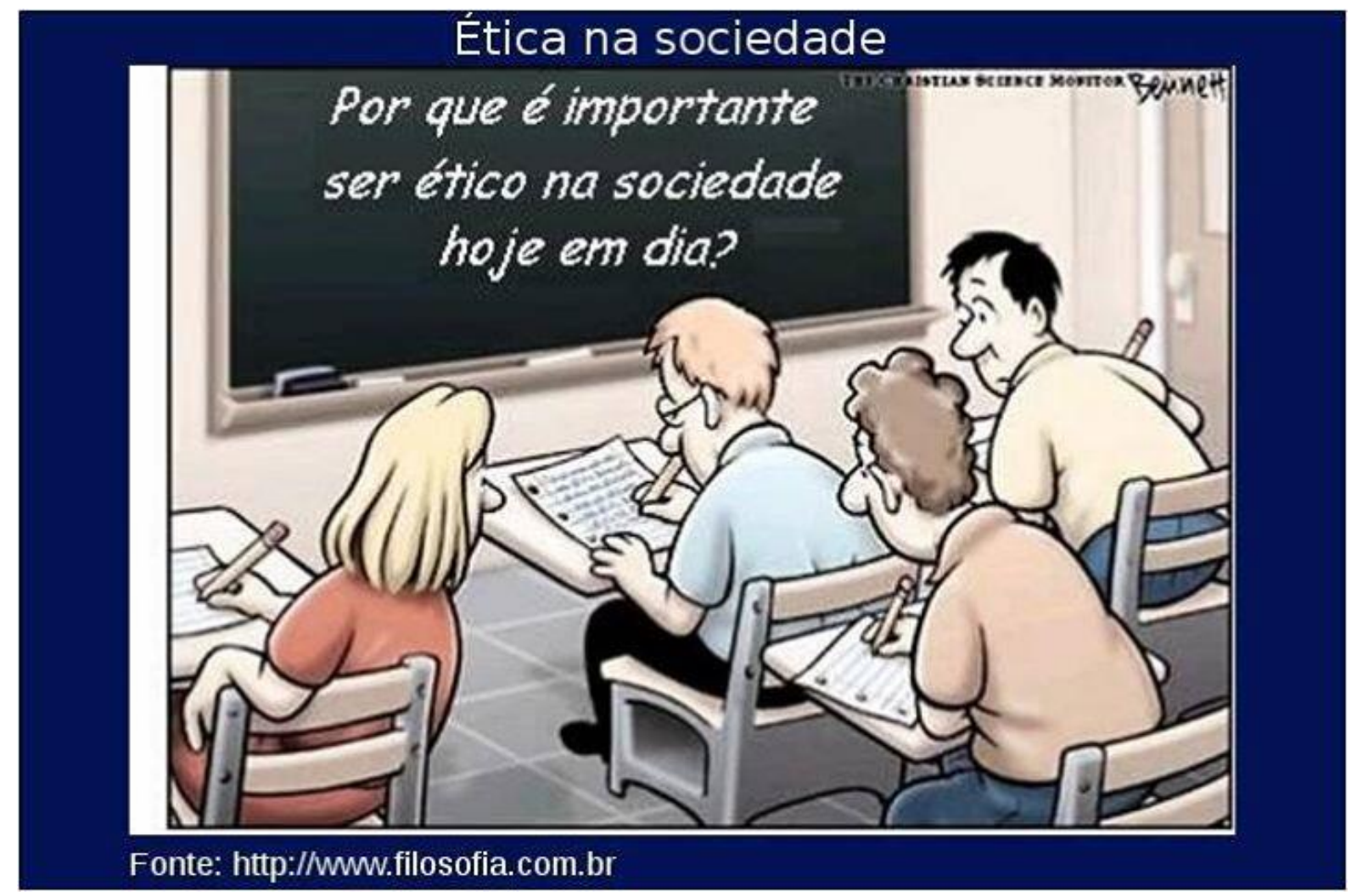


Surge também o questionamento quanto aos valores sociais e o respeito ao próximo quando "não só na sociedade de hoje em dia, mas é preciso ser ético sempre! aceitar e respeitar a heterogeneidade de sexo, as diferenças sociais e econômicas, pois só assim se faz uma sociedade com valores morais e virtudes!" ou então quando se argumenta que "ao menos para manter a paz entre organizações. Imagine se um país começasse a agir de forma antiética com outro? Com a tecnologia atual, é capaz que se gere uma guerra que acabe com o mundo inteiro." É possível verificar que os argumentos são amplos e envolvem questões claras dos possíveis problemas causados por falta de ética ou da importância da ética para as relações interpessoais.

Resultou-se uma unanimidade por parte dos comentários reforçando a importância da ética, inclusive com argumentos diferentes, como no caso "hoje em dia para alguns uma pessoa ter ética é porque a pessoa é "nerd" e tal, mas não é isso gente, se tu quer ser uma pessoa verdadeira de bem com pessoas do bem, você vai ter ética" ou "a ética é necessária para haver uma boa relação entre as pessoas. Quem é ético é confiável, o que ajuda até na hora de uma entrevista de emprego, mas, acima de tudo, na convivência com as outras pessoas, sendo gentil e educado, fazendo a coisa certa sempre." Observase a ética não só na escola mas em todos os ambientes, envolvendo desde comportamento até relacionamento e postura profissional.

\section{Diferenças entre as escolas de 1969 e 2009}

A escola, assim como a sociedade, passa por mudanças em sua estrutura e em seu estilo de trabalho. A postura dos professores atuantes na escola, bem como a maneira como são vistos pela sociedade, teve mudanças nas últimas décadas, conforme a figura 4. De acordo com as concepções dos jovens isso se deve a alguns motivos, como, por exemplo, "digamos que em 1969, a mentalidade dos pais era outra: os filhos deveriam ser obedientes e crescerem dignos para serem bons adultos. Além do mais, estudo não era para todos, então não deveria ser desperdiçado. Já agora, em 2009, é quando aquelas crianças da época de 1969 são os pais. Talvez eles não queiram que os filhos passem por tudo que eles passaram sem motivo aparente: afinal, o estudo é bem mais acessivo hoje." 
Imagem 3

Pais, estudantes e professores de 1969 e 2009.

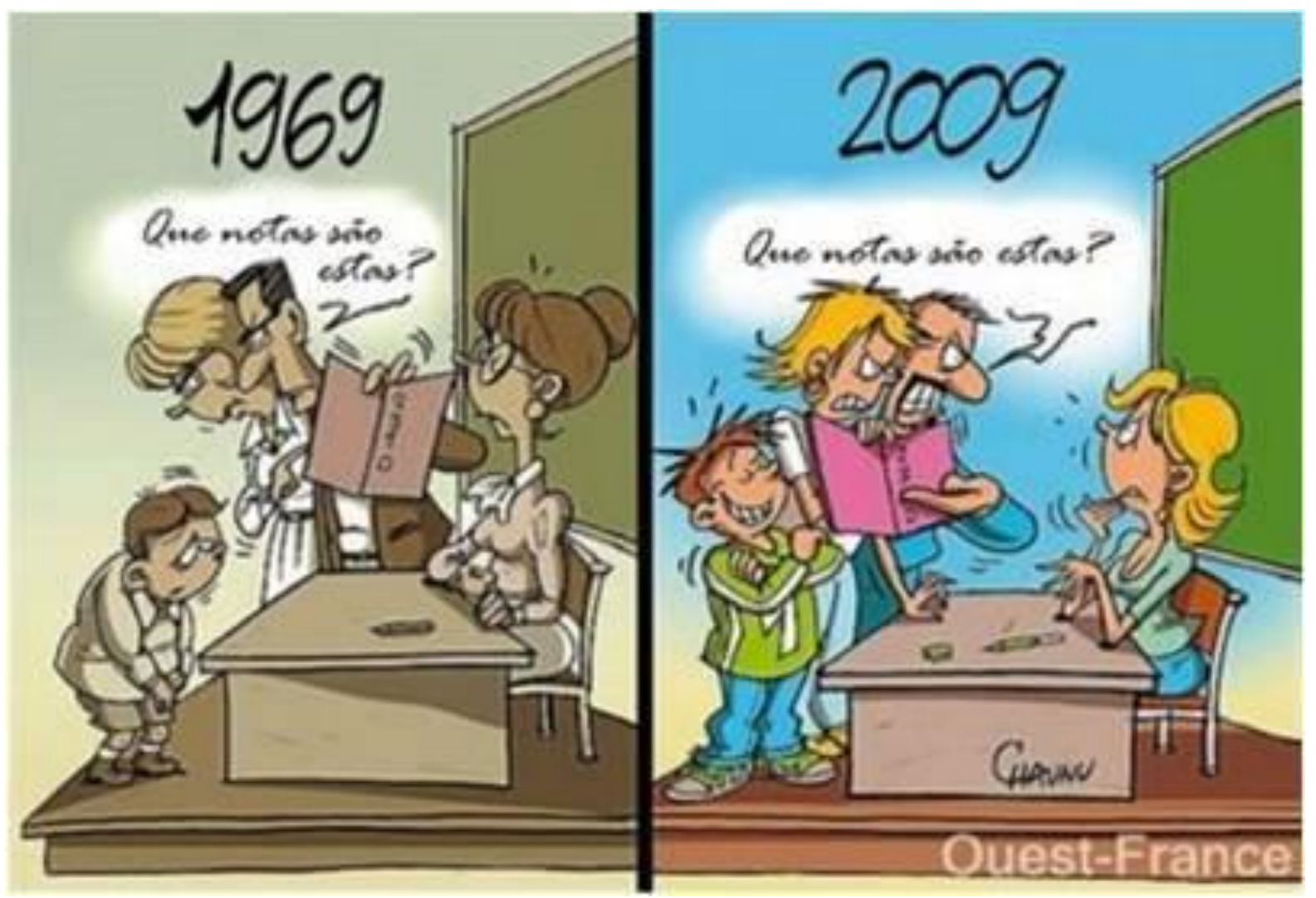

Essa argumentação implica dizer que esses pais do presente, que eram estudantes no passado, sofreram com a escola de alguma forma e que agora não acreditam ser mais necessário tal sofrimento, pois as escolas são mais acessíveis agora. O mesmo sujeito da observação anterior, ainda acrescentou: "E também, aliado a falta de tempo dos pais com os filhos, falta-se disciplina. Providencia-se uma infância melhor mas uma criação pior, pois gera-se a criação de crianças mimadas que acreditam que as pessoas ao seu redor simplesmente não entendem o seu "potencial", mesmo que às vezes a culpa seja totalmente do aluno" demonstrando que existe um contraponto ou uma implicação negativa nessa mudança de paradigma.

Em geral os jovens estudantes argumentaram que no período em que seus pais eram alunos, aparentemente havia um rigor e uma cobrança maior por parte de pais e escolas, e que atualmente, a cobrança e a preocupação com a educação e com o comportamento não são mais os mesmos. Alguns sugeriram que isso ocorre em função do grande volume de trabalho que os pais têm e que acabam permitindo que os filhos "façam o que querem", tornando-se "escravos dos próprios filhos." Além de os pais "estarem mais superprotetores", em função de terem menos filhos por casais, o que faz com que esses pais "mimem" mais os seus filhos, ou seja, os pais estariam "abdicando bastante da sua autoridade."

Foi sugerido, ainda, que "antigamente além do estudo ser melhor a coisa era mais séria" e que "a classe dos professores hoje em dia não é mais tanto levada a sério", sugerindo que a educação está perdendo a qualidade e a seriedade, conforme segue: 
"não tinha essa de arrumar desculpas para não copiar, os alunos eram dedicados e respeitavam os professores, hoje em dia esse respeito de antigamente não existe mais, se o aluno roda em uma prova só falta bater no professor ele e os pais, mas existem exceções, mas não deveria ser assim pois é obrigação do aluno estudar, porque a maioria dos estudantes não trabalham, então o que resta é estudar para que um dia possam ser alguém na vida". Isso também pode ser observado em "antigamente havia muito mais respeito dos pais com os professores, hoje se pensa que eles não são tão importantes e são substituíveis, o que está muito errado."

\section{Significados das épocas}

"O passado, para mim, seria a atmosfera de conhecimento e atitudes praticados e estudados por nós e pelas pessoas ao nosso redor em um tempo anterior ao nosso. Essas servem como experiência para ações futuras. Já o presente é a atmosfera das ações que realizamos no dia-a-dia: é o que achamos, o que pensamos, o que fazemos e o que defendemos no agora. Enquanto isso, o futuro é a atmosfera onde se encontra tudo que queremos alcançar e tudo que o tempo nos trará".

"Passado, presente e futuro, não passa de tempos impostos pelo ser humano à ele mesmo, como se fosse um prazo de validade. As pessoas vivem em torno do relógio, correndo. ou não, atrás dos seus objetivos, sempre como se fosse o último dia. Muitas deixam de aproveitar coisas raras, para garantir um futuro melhor. Eu prefiro viver o presente, e não me preocupar tanto com o futuro, mas sim, faço planos, tenho sonhos.. e quero ter uma vida tranquila. Mas não abro mão das coisas que quero fazer agora."

Imagem 4

Presente, passado e futuro.

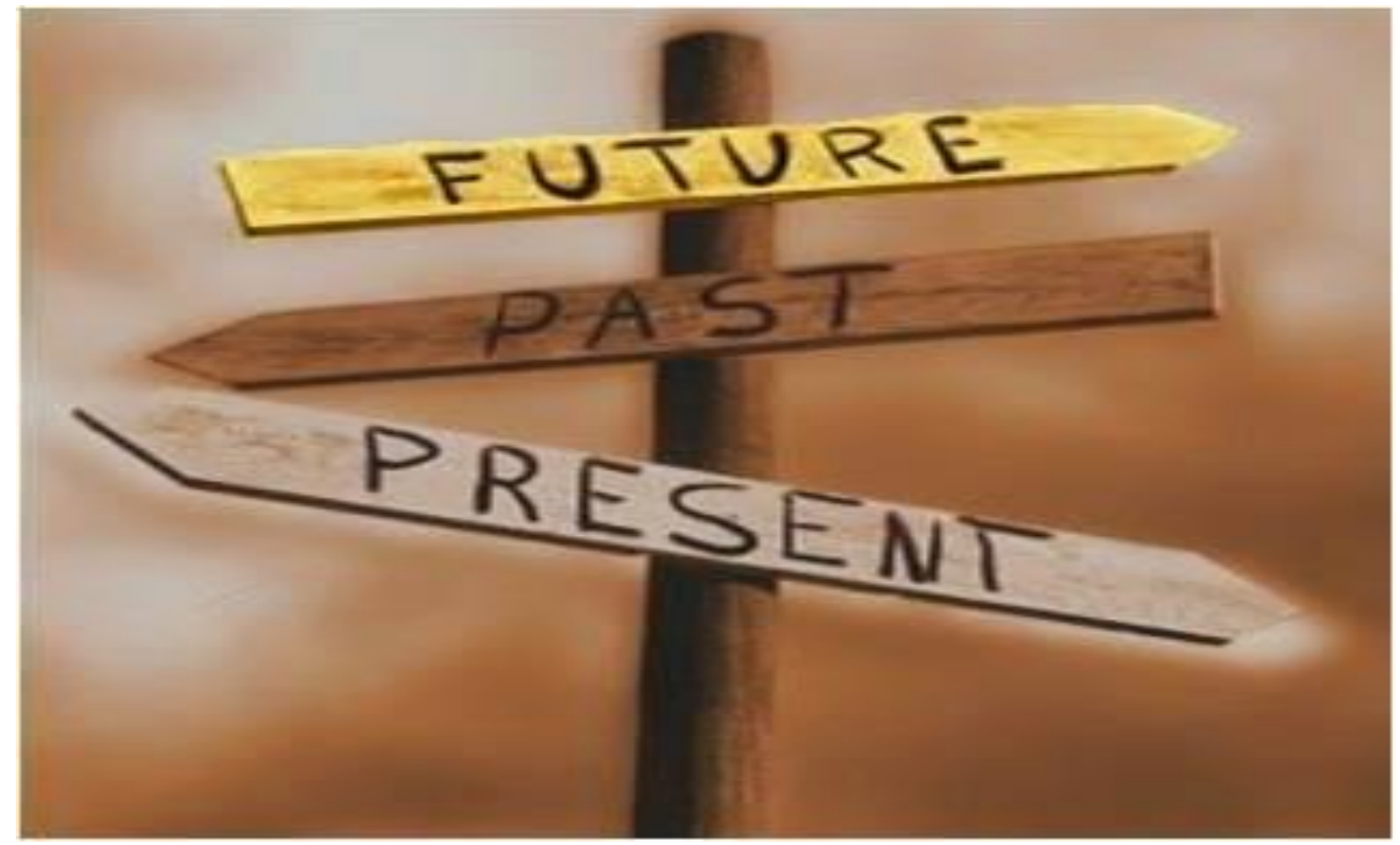


"Passado estudei presente continuo estudando para que no futuro eu seja alguém na vida... e nós jovens temos a obrigação de passar isso para os menores pois assim como nós seremos o futuro de amanhã eles também serão então vamos estudar gente."

"Nada mais é do que a nossa vida. Passado, presente e futuro fazem parte dela e estão presentes em tudo q fazemos. A única providência a ser tomada é não pensar de mais no futuro e nem se lastimar demais por coisas que aconteceram no passado. precisamos ter consciência de que o que mais importa é o presente, o hoje, o agora."

\section{Considerações finais}

O presente trabalho buscou analisar as percepções dos jovens em relação á escola, suas reações e sentimentos com as mudanças pelas quais as instituições passam ao longo do tempo. Com as postagens realizadas no Facebook e as entrevistas foi possível verificar um distanciamento dos jovens em relação às questões da escola. O perfil Zoreia, teve 115 amigos, no entanto, a grande maioria não participou das discussões, mesmo com a motivação da premiação. Ainda assim, os participantes demonstraram um senso de crítico sobre a escola e o meio em que está inserida, como identificado por Abramovay (2005), como uma busca pela liberdade, uma não conformidade com a realidade, que não os motiva, que não os assegura o futuro.]

Esse sentimento de que as instituições/pessoas não se adequaram aos novos tempos também aparece quando questionados em relação a moda, agora eles aparecem como donos de si próprios, ignorando todo e qualquer modismo, porém esses comentários podem ser facilmente destruídos, ao olharmos para os próprios jovens na sala de aula, utilizado as mesmas peças de roupas, que se estivessem de certa forma uniformizados. Outro aspecto a ser destacado em relação ao modo de se vestir é o sentimento de mudança de época como citado por vários estudantes, o que é deste tempo e o que é do tempo passado, novamente aparecendo o sentimento de que as instituições ou pessoas que não se adequaram aos novos tempos.

Quando se questionou sobre a ética surgiram comentários sobre o sentido de seres cidadãos, de humanos, de ética a ser mantida, ou seja, apesar das críticas com o modelo atual do ambiente escolar, distante dos interesses dos jovens, mesmo com o sentimento de que as instituições estão desatualizadas, o conceito de ética perdura, buscando o fim de preconceitos e a valorização da paz. Quando perguntado a respeito das diferenças do modelo de escola do passado e a escola atual pode ser entendido que há uma falta de limites, os quais deveriam ser impostos pelos próprios pais e professores. Os pais deixam que os filhos "façam o que querem" ou pais "escravos dos próprios filhos": estas frases demonstram que os jovens acreditam que precisam de mais rigor, não culpam os pais ou professores, descrevem como causa a falta de tempo, a experiência negativa de seus pais e a desvalorização dos professores.

A última postagem trouxe o sentimento de não preocupação com o futuro e sim com o presente, repudiando o planejamento. Isso pode ser compreendido pela mudança da nossa época em que o estudo, o diploma, o casamento não são mais considerados imudáveis: "perante estruturas sociais cada vez mais fluidas, os jovens sentem a sua vida marcada por crescentes inconstâncias, flutuações, reversibilidades" (Pais, 2006, p 11).

Os jovens pesquisados que apresentam sentimento de repulsa ao velho, querem instituições atualizadas, querem o novo e para isso descrevem o uso da tecnologia como 
ferramenta básica, reprovam a falta de limites e a falsa liberdade agora dada pelos pais, acreditam na ética e acham que é possível um mundo mais igual, não planejam o futuro de forma concreta, alguns até acreditam que o estudo pode trazer um futuro melhor, mas o sentimento geral é de viver o presente, melhor deixar acontecer: "A única providência a ser tomada é não pensar de mais no futuro e nem se lastimar demais por coisas que aconteceram no passado. precisamos ter consciência de que o que mais importa é o presente, o hoje, o agora". Na realidade não há mais o sentimento da "recompensa futura" em função do "sacrifício atual".

\section{Referências}

ABRAMOVAY, Miriam. Estar no papel: cartas dos jovens do ensino médio. Brasília: Unesco, 2005.

ABRAMOVAY, Miriam; ANDRADE, Eliane Ribeiro; ESTEVES, Luiz Carlos Gil (org.). Juventudes: outros olhares sobre a diversidade. Brasília: MEC-Unesco, 2007.

BRASIL. Ensino médio: construção políticas - sínteses das salas temáticas. Brasília: MEC, 2003.

BRASIL. Juventudes: outros olhares sobre diversidade: Brasilia: MEC, 2007.

CNE. Parecer CNE/CP9/2001. Brasília: CNE, 2002.

CHRISTOPLE, Micheline. A legislação sobre educação tecnológica no quadro da educação profissional brasileira. <http:/tupi.fisica.ufmg.br/michel/docs/Artigos e textos/ Gestao de cooperativas/educacao\%20tecnologica.pdf>. Acessado em 24 jun.; 2013.

CRESPO, Karina Loreto; RUIZ, Álvaro Elgueta; PARRA, Alejandro Riffo. Motivación, consumo y apreciaciones de Facebook por parte de jóvenes universitarios: El caso de la Red UCSC Chile. Ultima décad., Santiago, v. 17, n. 31, dic. 2009. Disponible en $<$ http://www.scielo.cl/scielo.php?script=sci arttext\&pid=S0718-22362009000200008\&lng= es\&nrm=iso>. Accedido en 24 jun.; 2013.

FANFANI, Emilio Tenti Cultura jovem e cultura escolar: documento apresentado no seminário Escola jovem: um novo olhar sobre o ensino médio. Brasília: MEC, 2000.

GIL, Antônio Carlos. Métodos e técnicas em pesquisa social. São Paulo: Atlas, 1999.

LDB, Lei de Diretrizes e Bases da Educação Nacional. Brasília: CNE, 1996.

OLIVIER, Bert. Facebook, cyberspace, and identity. Psychol. Soc., Cognella, n. 41, 2011. Available from <http://www.scielo.org.za/scielo.php?script=sci arttext\&pid=S101560462011000100004\&lng=en\&nrm=iso $>$. Access on 25 jun.; 2013.

PAIS, José Machado; Buscas de si: expressividades e identidades juvenis. Rio de Janeiro: Jorge Zahar, 2006.

PEREIRA, Alexandre Barbosa; Aprendendo a ser jovem: a escola como espaço de sociabilidade juvenil. CONGRESSO BRASILEIRO DE SOCIOLOGIA, 13, 2007. Anais ... Recife: SBS, 2007.

RAMPAZZO, Lino. Metodologia cientifica. São Paulo: Loyola, 2010.

REA, Louis; PARKER, Richard. Metodologia da pesquisa: do planejamento a execução. São Paulo: Pioneira, 2000. 
RODRIGUEZ, Edwin Cruz; LESLEY Wood; Los movimientos sociales, 1768-2008. Desde sus orígenes a facebook, barcelona, crítica, 366 P. anal. polit., Bogotá, v. 24, n. 73, dec. 2011. Available from <http://www.scielo.org.co/scielo.php?script=sci arttext\&pid=S0121$\underline{47052011000300009 \& \operatorname{lng}=e n \& n r m=\text { iso }}>$. Acesso em 24 jun., 2013.

Alexsandra Matos Romio é professora no Colégio Técnico Industrial de Santa Maria.

Endereço: Avenida Roraima, 1000 - Colégio Técnico Industrial de Santa Maria 97015-970 - Santa Maria - RS - Brasil.

E-mail: alexsandra@ctism.ufsm.br.

Andréia Lucimar Silva de Lima é técnica administrativa em educação na Universidade Federal de Santa Maria.

Endereço: Avenida Roraima, 1000 - secretaria do curso de Agronomia - 97015-970

- Santa Maria - RS - Brasil.

E-mail: andreialslima.lima7@gmail.com.

Iliane Colpo é técnica em contabilidade da Universidade Federal de Santa Maria. Endereço: Avenida Roraima, 1000 - Pró-Reitoria de Administração - 97015-970 Santa Maria - RS - Brasil.

E-mail: ilicolpo@gmail.com.

Claudia Cisiane Benetti é professora adjunta na Universidade Federal de Santa Maria.

Endereço: Avenida Roraima, 1000 - Centro de Educação - 97015-970 - Santa Maria - RS - Brasil.

E-mail: cisiane@terra.com.br.

Recebido em 3 de junho de 2014.

Aceito em 18 de outubro de 2014. 